\title{
Expression of Symbols and Their Message of Peace and Conflict in Identity Drawing Map (IDM): Arab and Jewish Students
}

\author{
Rachel Hertz-Lazarowitz ${ }^{1}$, Abeer Farah ${ }^{2}$, Tamar Zelniker ${ }^{3}$ \\ ${ }^{1}$ Faculty of Education, University of Haifa, Haifa, Israel \\ ${ }^{2}$ School of Social Work, University of Haifa, Haifa, Israel \\ ${ }^{3}$ Tel-Aviv University, Tel-Aviv, Israel \\ Email: rachelhl@edu.haifa.ac.il, Abeer.farah@gmail.com, tamar@post.tau.ac.il
}

Received April 11 ${ }^{\text {th }}, 2013$; revised May 12 $2^{\text {th }}, 2013$; accepted May $20^{\text {th }}, 2013$

\begin{abstract}
Copyright (c 2013 Rachel Hertz-Lazarowitz et al. This is an open access article distributed under the Creative Commons Attribution License, which permits unrestricted use, distribution, and reproduction in any medium, provided the original work is properly cited.
\end{abstract}

\begin{abstract}
In 2008, we conducted a large scale study following our methodology developed for the analysis of drawings to assess identity (Hertz-Lazarowitz, Farah, \& Yosef-Meitav, 2012). We gathered interviews and asked for drawing Identity Drawing Map from 184 students aged from 20 - 30 years. The symbols in the drawings were grouped in 5 categories: religious, national, emotional, secular-cultural and nature and person figure symbols. The most frequent symbols were related to the nature and person figure category, and the least frequent were symbols from the secular-cultural category. The symbol categories with most indicative of identity conflicts were religious and national. The Arabs had more conflicted and complex IDM messages than Jews and the evaluation of their emotions were less positive and less optimistic than the Jews. The IDM methodology revealed the complex and multi-layered expression of identity construction. These findings can provide better understanding into the mechanism of identity construction in a society and the University context which has been conflict ridden for many decades.
\end{abstract}

Keywords: Hyphenated Identity; University of Haifa; Jews; Arabs; Identity Drawing Map

\section{Hyphenated Identity}

The theory of "Hyphenated Identity" (HI) argues that people living in complex political-social contexts construct a "new identity" that includes many identities depended on the sociocultural and political contexts. Research had documented that young adults include various sub-identities and "live on the hyphen", between identities found in contrast vs. harmony (Farah \& Hertz-Lazarowitz, 2009).

Israeli society is bi-national, comprising a Jewish majority and an Arab minority. For many years, the Arab population in Israel was referred to by the majority as "the Arabsi", as a matter of distinction from "the Jews". Throughout the years, definitions have changed and developed for and within each group Jews and Arabs are now defining themselves by more identity terms. Especially the Arab minority in Israel added many HI, among their terms of collective identity: Palestinians, ArabPalestinians, and Palestinian citizens of Israel (Yosef-Meitav, 2008).

Since the establishment of the State of Israel in 1948, identity has been a core concept that challenged Israeli society. Particularly challenging has been the term Jewish, as it refers to both religion and nationality (Herman, 1977). Young Arabs and Jews have encountered complex political changes, adjusting to greater diversity of ethnicity, culture and religion, while continuing to live in the context of an intractable conflict (Jarymowicz \& Bar-Tal, 2006; Rouhana, 2004a; White Stephan,
Hertz-Lazarowitz, Zelniker, \& Stephan, 2004). Over time, identity definitions in Israel changed moving from simple or binary to multiple and more complex identities (Ghanem, 2006; Maoz, Steinberg, Bar-On, \& Fakhereldeen, 2002). Especially Arabs and Jewish immigrants negotiated their identity via a complex course of action (Gerges, 2003). The aim of this study is to explore the deeper meaning youth in Israel assign to their identities.

\section{The Context of the University of Haifa}

The University of Haifa is a unique environment for studying how nationality, religion, and ethnicity contribute to students' construction of their identity, and how identity in turn is related to students' perception of their experiences on campus. University of Haifa is a meeting place for Arab (Muslim, Christian, and Druze) and Jewish students, from different ethnicities. All the students are either religious or secular, with varied ethnic background; political orientation, as well as different calendars that mark their religious and civic life. Within this multifaceted context identities are constantly under reconstruction as young people live in a complex mixture of conflict and harmony.

Since 2001 and up to 2008 Hertz-Lazarowitz and a team of Arab and Jewish researchers conducted annual studies as part of a research seminar entitled "Social psychological aspects of the University”. The full questionnaire asks the students to rate attitude on a Likert scale and rates their perception of Haifa 
University (HU). In those studies students choosed one identity from a list, and there was an option to add an identity definition (Zelniker, Hertz-Lazarowitz, Peretz, Azaiza, \& Sharabany, 2009).

Generally, methods employed in identity research include surveys, interviews, and identity drawing map (IDM). In the 2001 to 2008 studies, background independent variables were Identity, nationality, and religion. The depended measures were scales of psycho-sociological variables composed of positive and negative perceptions of students' experiences on campus. Positive scales included multicultural experiences, democracy, contact, closeness, and friendship with students from the other group. Negative scales included feelings of discrimination, racism, desire for segregation, and political tension. All of the variables were measured using 1 - 5 Likert scales.

In general, Arabs and Jews were found to have similar positive perception of the university, with the Arabs being more positive than the Jews. The Arabs expressed greater desire for integration, but at the same time they also showed greater desire for segregation. Both groups viewed political tensions as an important variable exerting negative influence on life on campus. Arabs, mostly Muslims, who included the term Palestinian in their HI, were more negative about the university than the Christians and Druze and viewed the university as a space of racism and alienation (Hertz-Lazarowitz, Azaiza, Peretz, Zelniker, Kupermintz, \& Sharabany, 2007). The research on HU indicates that the groups that earn the most from academic studies is women in general and Arab women in particularly (Arar, Shapira, Azaiza, \& Hertz-Lazarowitz, 2013; Gilat \& HertzLazarowitz, 2009).

In addition to the measured employed in our 2001-2005 studies, 25\% of the participants in the 2006 and 2008 study were interviewed in order to explore identity construction. At the end of the interview students were given a blank page and were asked to write their identity definition. They were also asked to draw a picture expressing their identity and write text related to the drawing. Their written identity definition, plus the drawing, plus the text related to the drawing, constituted the Identity Drawing Map (IDM). This method followed the procedure used by Michelle Fine in her study of HI (Fine 1994). The maps were examined by qualitative and quantitative methods of analyses; and added important understanding of the $\mathrm{HI}$ in its current construction (Farah \& Hertz-Lazarowitz, 2009; HertzLazarowitz, Yosef-Meitav, \& Zoabi, 2007).

We assumed that in Israel we will also find $\mathrm{HI}$ and student that "live on the hyphen", between identities in contrast vs. harmony (Farah \& Hertz-Lazarowitz, 2009; Hertz-Lazarowitz, Yosef-Meitav, \& Zoabi, 2007). This study focuses is on the IDM methodology to explore HI in a UH mixed University. We aim to find differences as well as similarities in Arab and Jews based on using the IDM methodology.

\section{Method}

\section{Participants}

In the year of 2008, 76 Jews (27 from Ethiopia, 32 from Former Soviet Union, 17 born in Israel) and 109 Arabs (31 Druze, 35 Muslims and 43 Christian) participated in the study. All of them UH Students in their third year, from various departments participated voluntarily in the study. They created the IDM as part of the questionnaire; all of the 184 maps were documented and analyzed (Farah \& Hertz-Lazarowitz, 2009).

\section{Procedure}

Following a 90 minutes semi structured interviews; students were interviewed on their life in general and specifically on campus. At the end of the interview they were asked to write an identity definition, draw their identity map, and add a brief text related to their map (Yosef-Meitav, 2008; Hertz-Lazarowitz, Yosef-Meitav, Farah, \& Zoabi, 2010).

\section{Measures}

Coding in this study was based on method developed by Katsiafics, Hertz-Lazarowitz, Sirin. Fine, Yosef-Meitav, Farah \& Zoabi' (2008). Three coders proceed through three stages of coding the IDM:

1) Categorization of objects to groups of symbols: First, all objects in the drawing were counted. The total number of objects counted was 100 . Then up to 3 most salient objects were coded in the fitting category of symbols and entered later to the SPSS analysis. The five categories were:

- Religious symbols : Mosque, Synagogue, and Cross;

- National symbols: geographical maps, Israel flag, Palestinian flag;

- Emotional symbols: Heart, family, sadness-tears;

- Secular and Cultural symbols: T.V, books, university, village;

- Nature and person figure: person, parts of body, animals, buildings, flowers.

2) The massage of the maps: The coders defined the IDM according to the following distinctions:

- Integrated maps: If symbols of identities (at least two) and text were blended in integration;

- Conflicted maps: if symbols of identities (at least two) and text were depicted with high tension, and intense rage;

- Separated/parallel Maps: if symbols of identities (at least two) and text were separated or parallel.

The above three types of the massages could appear in three types of maps:

- Complex/mixed map: Concomitant expressions of the different types of messages (e.g., both integrated and separated, or other combinations of message types);

- Personal map: Symbols (more than half) expressing personal attributes (e.g., personal talents or constraints);

- Collective map: symbols (more than half) expressing mostly group attributes (e.g., religious symbols).

3) Evaluation of emotion: The coders used 12 emotions. Positive emotions such as satisfaction, pride, hope, happiness, elevation; and negative emotions such as anxiety, anger, sadness, hostility, contempt, shame, disgust. Here also, the coders decided if they are very certain that the emotion is presented in the map (3) or very uncertain (1).

\section{Reliability}

The coders were three students of psychology and education on their B.A and M.A degree. They were trained 12 hours by the main researcher. Each coder received an identity map, read the text written beside the identity map and described it. They start working individually and then rotated in pairs. At the same time they wrote a protocol which provide a basis for testing the reliability, the coders agreed $90 \%$ between them about the three stages of coding of the IDM (Hertz-Lazarowitz, Yosef-Meitav, \& Zoabi, 2007). 


\section{Results}

First we present six IDMs represent the six major groups of students: Arabs, all born in Israel (Muslims, Christians, and Druze), and Jews (Born in Israel, born in former Soviet Union, and Born in Ethiopia). The first two IDMs will be presented with descriptive analyses based on the students' background, the drawing and its related text. Afterwards we present four IDM with the very short explanation.

Then we move to the statistical analysis of category symbols, massages of the maps and emotional evaluation of all the IDMs ( $\mathrm{N}=184$ ) (Farah, Hertz-Lazarowitz, 2009).

\section{A': Arab Muslim Male}

\section{Background Information}

A' is 21 years old, single, traditional Muslim, Arab. He defines his identity as an Arab Palestinian who lives in Israel. He was born in Israel and lived in Arab village.

\section{The Text near the Map}

"Maybe my drawing map is influence by the coming independence day, but I feel that the flag meaning the Jewish Zionist flag of the state, is crashing our Palestinian and Arab identity. I draw the Palestinian flag on the soil because it is the soil of our land. The figure of Handala ${ }^{1}$ symbolize my Arab identity, the Israeli flag symbolize the occupation that hides both Handala and the Palestinian flag”.

\section{Map Analysis and Summary}

As appears in Figure 1, A' draw three national symbols in different sizes: a small Palestinian flag, a large sliced Israeli flag and a figure of Handala, the three symbols are collective symbols. The map expresses a massage of conflict between national and civic identities; the emotions expressed are sadness and other negative emotions

A' drew the Israeli flag big over the whole page, and drew under it a small Palestinian flag and a small figure of Handala standing in the side. He writes that he (the student) is not satisfied with life in Israel. The Israeli flag painted over the whole page; symbolize the consolidation and the oppression of the Palestinian people. Under the flag he drew Handala on the side of the page. On the legs of Handala he drew the Palestinian flag (on the bottom of IDM). The Israeli flag is overruling the Palestinian flag; and the figure Handala; which became a known symbol for the Palestinians occupation (see Note).

\section{S': Jewish Male Born in Ethiopia}

\section{Background Information}

S' is 28 years old, single, traditional Jewish. He defines his identity as a Jewish Ethiopian. He has born in Ethiopia and lives in Jewish settlement.

\section{The Text near the Map}

"I am a Jewish man that immigrated to Israel from Ethiopia, I am very pleased here, I want to continue living in the land of Israel, I want to grow roots, develop and help the Ethiopian

${ }^{1}$ From approximately 1975 through 1987 Naji Al-Ali created cartoons that depict the complexities of the plight of Palestinian refugees. These cartoons are still relevant today and Handala, the refugee child who is present in every cartoon, remains a potent symbol of the struggle of the Palestinian people for justice and self-determination. community. As my family has adapted to the new state and overcome some difficulties, I want other Ethiopian families develop and always remained in the land on Israel”.

\section{Map Analysis and Summary}

As appears in Figure 2, S' drew many symbols in four categories: National: Three flags: An Israeli flag, an Ethiopian flag and a map of Israel, Religious: Star of David; Secular and Cultural: An Ethiopian house (the hot), Nature and Person figure he draws himself. Some symbols are collective (Israeli flag and Ethiopian flag) and some are personal symbols (a human figure and $\mathrm{w}$ house). The map expresses an integral massage, and expresses positive emotions such as proudness, hope and elevation.

S' draw a human figure, his face is colored dark blue with curly hair, on his body he draw a map of Israel. Above the figure he draws a large Israeli flag, around the flag he draws small lines, and in the right side of the flag he draws two stars of David. At the left side of the flag he draws the Ethiopian with colors. Under the flag of Ethiopia S' draw a straw hut which typical in Ethiopia. S' defined his identity as Jewish-Ethiopian, he writes about the close connection with the Ethiopian community and his desire to help them. The flag and the map of Israel are symbols of being a Jews, But he draws also an Ethiopian flag, a home from Ethiopia and Ethiopian human figure.

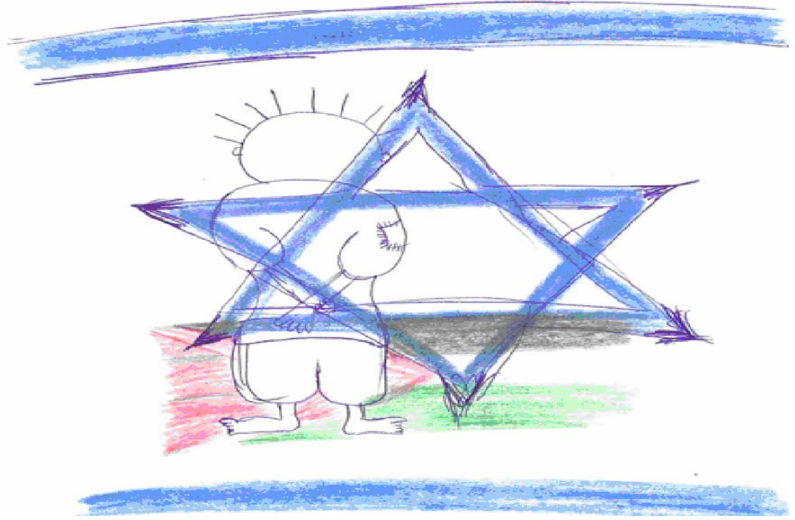

Figure 1.

The IDM.

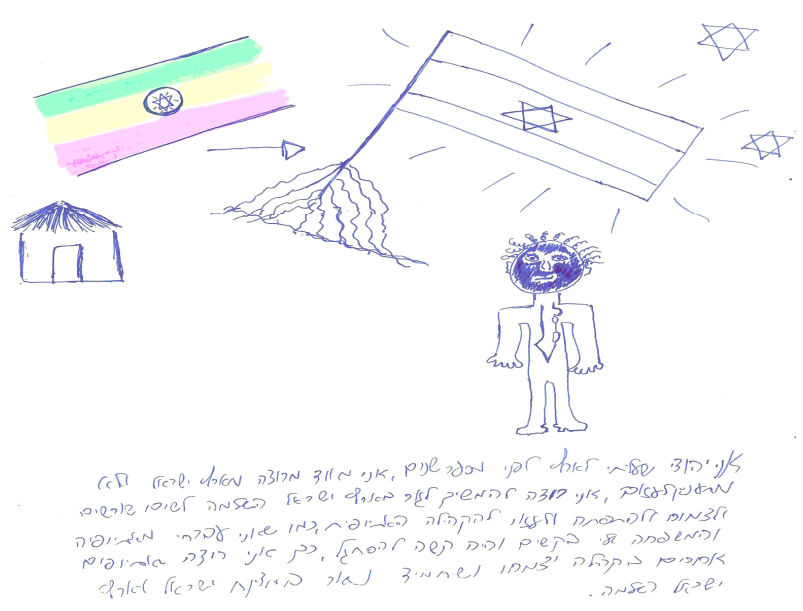

Figure 2.

The IDM. 
He strongly values his national identity and his connection to the Ethiopian community

As shown in Figure 3, the student draws in the middle the Star of David with two branches of olive tree by each side, and symbols of gender. She draws airplane and write the words peace and war.

As shown in Figure 4, the students draw Shabbat candles as a religious symbol, a women as a gender symbol, Israeli flag as a national symbol, a shirt and mounts as a culture symbol.

As shown in Figure 5, the symbols are connecting Christianity (Cross), Muslim Hillal, Jewish Star of David, and the Druze diamond, expressing coexistence and peace. the students write that: "I hope to be peace in Israel which is a is multi religious country"

As shown in Figure 6, She draws a Cross which symbolizes the Christianity. She writes in Hebrew: "the cross represent my great love to my religion". She draws a Palestinian and Israeli flag and feels conflict between them, she writes beside it: "I would like to define my civic identity as Palestinian and not as Israeli and this option doesn't exist in the ID". She draws a third flag and write "motherhood" in Arabic and writes: "I wrote motherhood because this overcomes all identity hardships”.
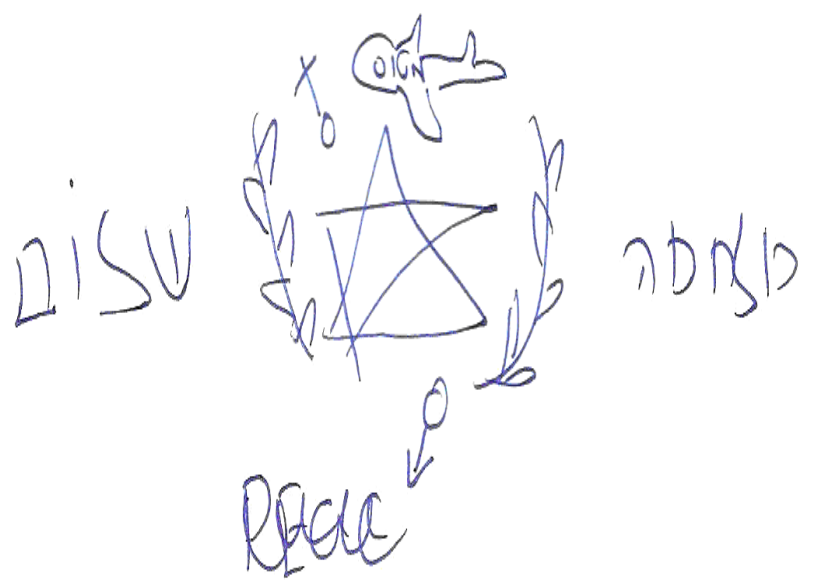

Figure 3.

J', Jewish female born in former Soviet Union.

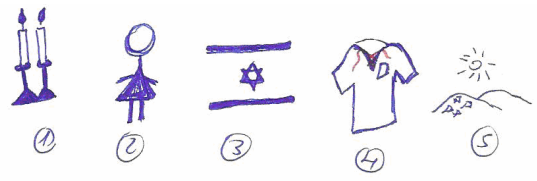

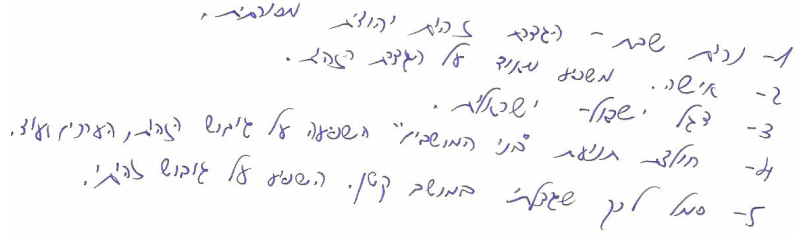

Figure 4.

F', Jewish female born in Israel.

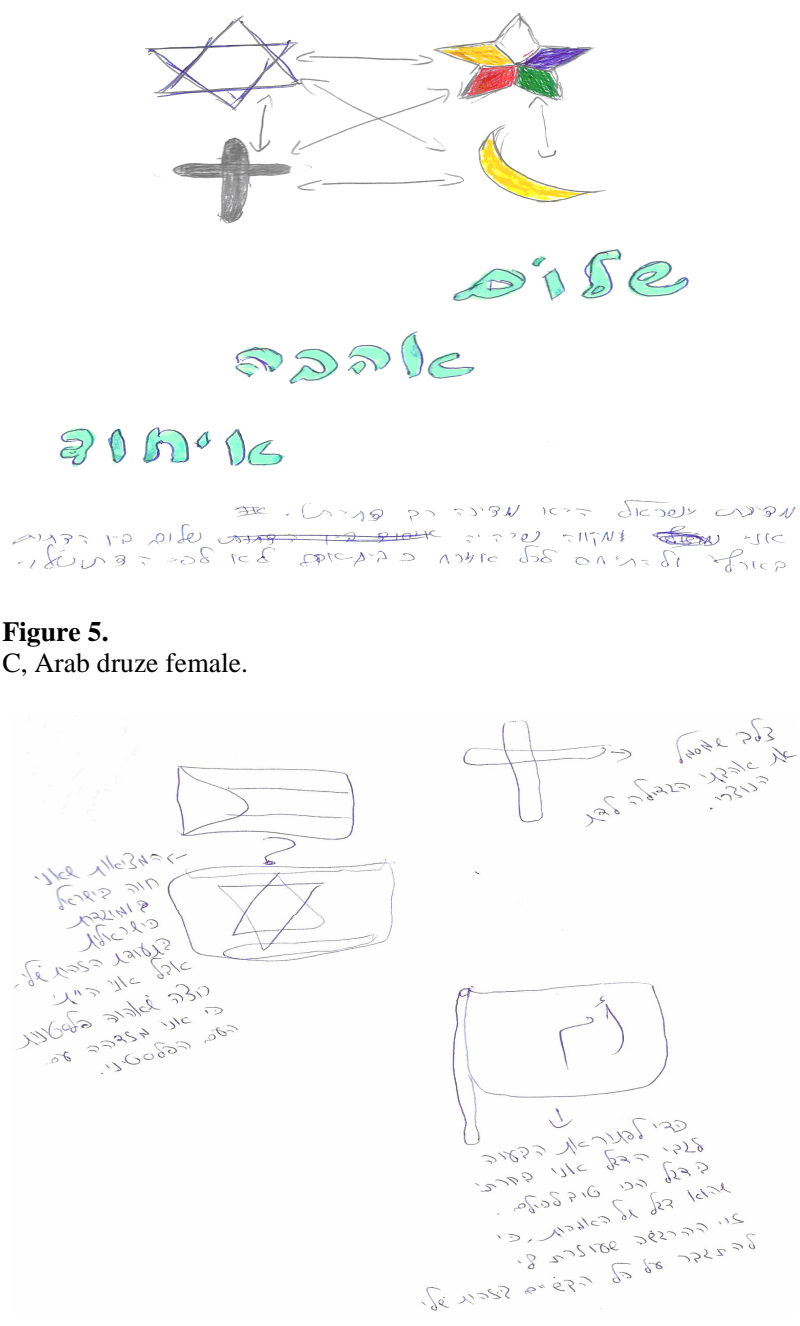

Figure 6.

F, Arab christian female.

\section{Statistical Analysis}

Similarities between Arabs and Jews, the two groups generated the same symbol categories and had similar percentages of symbols in each of the categories. For both groups, percentages of Nature and person figure symbols were highest; followed by national and emotional Categories, as shown in Table $\mathbf{1 .}$

Arabs have more religious symbols and emotional symbols. Jews have slightly more Secular-cultural and Nature and person figure. It proves that both groups express their identity by the same categories with nature and person symbol that highest and secular and culture the least, as shown in Table 1.

We will look now at the frequencies of symbols within each category. When we calculate and mean for each category within each national group by dividing the frequency of symbols by category and divided it by the total of the symbols separately for Jews and Arabs.

When we look specifically at the national category, we found that the most frequent symbols was drawing the flag, the Israeli flag $38 \%$ of the Jews and the Palestinian flag $15 \%$ of the Arab, interestingly the Druze flag appear at the $13 \%$ of the Arabs map, as shown in Table 2.

As mentioned in Table 3, for the religious symbols the most 
Table 1.

Summary of category of symbols for Jews and Arabs.

\begin{tabular}{ccc}
\hline & Arabs \% & Jews \% \\
\hline Religious & 17 & 13 \\
National & 24 & 24 \\
Secular-cultural & 11 & 14 \\
Emotional & 21 & 19 \\
Nature and person figure & 27 & 30 \\
\hline
\end{tabular}

Table 2.

National category by Arab and Jews.

\begin{tabular}{ccccc}
\hline \multirow{2}{*}{ Symbols } & \multicolumn{3}{c}{ Arabs } & \multicolumn{3}{c}{ Jews } \\
\cline { 2 - 5 } & $\mathrm{N}$ & $\%$ & $\mathrm{~N}$ & $\%$ \\
\hline Israeli Flag & 8 & 9 & 26 & 38 \\
Palestine Flag & 13 & 15 & 2 & 3 \\
Druze flag & 11 & 13 & - & 0 \\
Maps & 8 & 9 & 3 & 4 \\
Ethiopian flag & - & - & 6 & 9 \\
Olive tree & 1 & 1 & 1 & 2 \\
Total of symbols & 88 & 100 & 68 & 100 \\
\hline
\end{tabular}

Table 3.

Religious category by Arab and Jews.

\begin{tabular}{ccccc}
\hline \multirow{2}{*}{ Symbols } & \multicolumn{2}{c}{ Arabs } & \multicolumn{2}{c}{ Jews } \\
\cline { 2 - 5 } & $\mathrm{N}$ & $\%$ & $\mathrm{~N}$ & $\%$ \\
\hline Star of David & 10 & 15 & 12 & 33 \\
Cross & 18 & 25 & - & \\
Hilal (Islamic moon) & 7 & 10 & 1 & 3 \\
Druze star & 5 & 7 & 1 & 3 \\
Mosque & 1 & 1 & 2 & 6 \\
Torah & - & - & 2 & 6 \\
Candles & 1 & 1 & 1 & 3 \\
Clothes & 2 & 3 & - & \\
holy food/objects-wine, bread & - & - & 2 & 6 \\
Total of symbols & 71 & 100 & 35 & 100 \\
\hline
\end{tabular}

frequent symbol was the Star of David 33\% for Jews and 15\% for Arabs, followed by the Christian cross $25 \%$, Hilal $10 \%$ and Druze star $7 \%$ for the Arabs.

Frequency of emotional symbols were high in general, face smile $52 \%$ by the Jew and $33 \%$ by the Arabs, relationship in the family and heart were $22 \%$ for that Arabs and $19 \%$ for Jews, as shown in Table 4.

As mentioned in Table 5 for map massages, Arabs and Jews did not differ in integrated massage of maps, Arabs were higher
Table 4.

Emotional category by Arab and Jews.

\begin{tabular}{ccccc}
\hline & \multicolumn{2}{c}{ Arabs } & \multicolumn{2}{c}{ Jews } \\
\cline { 2 - 5 } & $\mathrm{N}$ & $\%$ & $\mathrm{~N}$ & $\%$ \\
\hline Face smile & 23 & 33 & 25 & 52 \\
Letter word & 23 & 33 & 9 & 19 \\
Relationships: Family & 9 & 13 & 7 & 15 \\
Heart & 6 & 9 & 2 & 4 \\
Face-anger & 3 & 4 & 1 & 2 \\
Tears & 2 & 3 & - & - \\
Family-mother & 2 & 3 & 2 & 4 \\
Face-Fear & 1 & 2 & 2 & 4 \\
Total of symbols & 69 & 100 & 48 & 100 \\
\hline
\end{tabular}

Table 5.

Map massages by Arabs and Jews.

\begin{tabular}{cccccc}
\hline & \multicolumn{2}{c}{ Arabs N $=109$} & \multicolumn{2}{c}{ Jews N $=76$} & \multirow{2}{*}{$\mathrm{t}$} \\
\cline { 2 - 5 } & $\mathrm{M}$ & $\mathrm{S} . \mathrm{D}$ & $\mathrm{M}$ & $\mathrm{S} . \mathrm{D}$ & \\
\hline Integrated & 2.00 & .91 & 1.85 & .84 & - \\
conflicted & 1.34 & .68 & 1.17 & .44 & $2.03^{*}$ \\
Separated & 1.36 & .67 & 1.34 & .62 & - \\
Complex & 1.37 & .62 & 1.12 & .50 & \multirow{2}{*}{$1.91^{*}$} \\
Collective & 2.09 & .91 & 2.00 & .88 & - \\
Personal & 2.13 & .86 & 2.25 & .82 & - \\
\hline
\end{tabular}

$(\mathrm{M}=1.34, \mathrm{SD}=0.68)$ than Jews $(\mathrm{M}=1.17, \mathrm{SD}=0.84)$ of the conflict massages $[\mathrm{t}=2.03, p<0.05]$. Arabs were also higher $(\mathrm{M}=1.37, \mathrm{SD}=0.67)$ than Jews $(\mathrm{M}=1.12, \mathrm{SD}=0.5)$ of the complex massages [ $\mathrm{t}=1.91, p<0.05]$.

From a list of 12 emotions we found that positive emotions (satisfaction, pride, hope, happiness, elevation) are most frequent by the Jews and also by the Arabs, and we did not find any significant differences in statistical terms. We found significant differences in tow negative emotions where Arabs emotions were evaluated more negatively in the categories of anger and sadness and less happy from the Jews, as mentioned in Table 6.

\section{Discussion}

Over a period of ten years there have been numerous social-political-psychological studies of Arab and Jewish students at the $\mathrm{UH}$, a campus which constitutes a microcosm of the strife-ridden Israeli society. Clearly, unresolved disputes between Jews and Arabs within Israel, and more broadly, within the Israeli-Palestinian conflict, influence the students' feelings, perceptions, identity, and behavior (Hertz-Lazarowitz, Zelniker, \& Azaiza, 2010; Hofman, 1988).

Given that the Arabs belong to a deprived and discriminated against minority, we expected the Arab students to differ from 
Table 6.

Evaluation of emotions by Arabs and Jews.

\begin{tabular}{cccccc}
\hline & \multicolumn{2}{c}{ Arabs N $=109$} & \multicolumn{2}{c}{ Jews N $=76$} & $\mathrm{t}$ \\
\cline { 2 - 6 } & $\mathrm{M}$ & $\mathrm{S} . \mathrm{D}$ & $\mathrm{M}$ & $\mathrm{S} . \mathrm{D}$ & - \\
\hline Anxiety & 1.12 & .40 & 1.04 & .20 & - \\
Anger & 1.39 & .78 & 1.21 & .50 & $1.86^{*}$ \\
Sadness & 1.35 & .66 & 1.18 & .45 & $2.01^{*}$ \\
Satisfaction & 1.94 & .80 & 2.09 & .80 & - \\
Pride & 1.97 & .95 & 2.17 & .91 & - \\
Hope & 1.97 & .94 & 1.80 & .88 & - \\
Happiness & 1.93 & .88 & 2.18 & .89 & $1.95^{*}$ \\
Hostility & 1.09 & .29 & 1.11 & .31 & - \\
Contempt & 1.05 & .21 & 1.01 & .11 & - \\
Shame & 1.00 & .10 & 1.05 & .28 & - \\
Disgust & 1.10 & .38 & 1.07 & .34 & - \\
Elevation & 1.59 & .70 & 1.61 & .73 & - \\
\hline
\end{tabular}

Jewish students in their identity construction and identity definitions in their IDM, but we found many similarities by categories and symbols.

For the Arabs, IDM messages entailed conflicted and complex messages more than Jews. The meaning of these messages for the Arabs was related to conflicts between the Arab minority and the Jewish majority. In the same time, among the Arabs we see more options to the drawing of national symbols specially the flag. In the first IDM, the most restricted of either the Israeli flag of the Palestinian is documented. However we also see in Figures $\mathbf{5}$ and $\mathbf{6}$ a broader presentation of a national flag and a search for a national flag that will include more options.

With respect to evaluated emotions, Arabs expressed more negative emotions than Jews, including anger and sadness. These emotions pertain to their difficult and discordant existence among the Jewish majority, and to the continuous oppressed existence of their Palestinian brothers under the Israeli occupation. At the same time, Arabs also had significantly less scores on happiness.

The most striking similarities between Arabs and Jews is the fact that the two groups generated the same symbol categories and had a similar content of IDM as expressed by the finding that percentages of Nature and person figure symbols were highest followed by national and emotional categories. One can suggest that for youth nature, person figure and emotional are very important.

The national and the religious symbols are the womb for contain conflict, oppression, unjust and occupation between Jews and Arabs; they do so by direct statements and by expression of emotions. The students express positive and negative emotion in regard to some national symbols. The war between religions and national symbols is very deep and painful, but we can imagine a future where all symbols receive respect and thus are accompanied by more positive emotion.

It is a positive sign that student can express both positive and negative emotion in regard to these symbols and toward the
University. But the Israeli-Jewish culture gives priority to the Jewish religious symbols in the daily life on campus and in the State. The reality today in Israel is that on one hand Arab can express their love for the Palestinian flag-but this flag is not recognized in Israel and thus is usually not included on campus as part of political approved demonstrations.

However with time and slowly, positive changes are taking place on campus: Some examples: more Arabs students enter high prestige department and mixed classrooms are the routine in all departments. Students live within an island of coexistence and cooperation for the last forty years. Inter-religion dialogue groups are forming: Prayer places are assigned to different religion groups: Few civil groups continue for years to create a dialogue and understanding sites for different groups. The holidays of all religions are now acknowledged by UH authorities, but still have to attend classes with some flexibility. Thus some can dream and imagine a reality where national and religious symbols will reach more acceptances and respect from UH authorities and vary groups of students.

\section{REFERENCES}

Arar, K. H., Shapira, T., Azaiza, F., \& Hertz-Lazarowitz, R. (2013). Arab women in management and leadership: Stories from Israel, New York: Palgrave Macmillan press. doi:10.1057/9781137319333

Farah, A., \& Hertz-Lazarowitz, R. (2009). Identity maps of Arab and Jewish youth on Haifa University campus. Quantities Research Report, Haifa: The Faculty of Education and the Jewish Arab Center, Haifa University. (Hebrew)

Fine, M. (1994). Working the hyphens: Reinventing the self and other in qualitative research. In N. Denzin, \& Y. S. Lincoln (Eds.), Handbook of qualitative research (pp. 70-82). California: Sage.

Ghanem, A. (2006). Civic developments among the Palestinians in Israel: The third annual book. Markaz Ibn Khaldun lil-Dirasat al-Inmaiyah.

Gilat, A., \& Hertz-Lazarowitz, R. (2009). Religious and non-religious Muslim women experience of empowerment in the private sphere (marriage/parenthood/family) (pp. 211-236). In F. Azaiza, C. H. Abu -Baker, R. Hertz-Lazarowitz, \& A. Ghanem (Eds.), Arab women in Israel: Current status and future trends. Tel-Aviv: Ramot Publishing House, Tel Aviv University. (Hebrew)

Gilat, A., \& Hertz-Lazarowitz, R. (2009). Women's experience of personal and gender empowerment through university studies: The case of Jewish and Arab religious and non-religious women (pp. 133148). In R. Hertz-Lazarowitz, \& I. Oplatka (Eds.), Gender and ethnicity in the Israeli academy. Haifa: Pardes publisher. (Hebrew)

Gerges, F. A. (2003). Islam and Muslims in the mind of America. Annals of the American Academy of Political and Social Science, 588, 73-89. doi:10.1177/0002716203588001006

Herman, S. N. (1977). Jewish identity: A social psychological perspective. Beverly Hills, CA: Sage.

Hertz-Lazarowitz, R., Rouhana, N., Hofman, J. E., \& Beit-Hallahmi, B. (1978). Curricular influence on identity among Jewish and Arab school students in Israel. Studies in Education, 19, 153-169.

Hertz-Lazarowitz, R., Azaiza, F., Peretz, H., Zelniker, T., Kupermintz, H., \& Sharabany, R. (2007). National identity and perception of the university as a context of coexistence VS a context of conflict (pp. 159-167) In G. Rahav, Y. Wozner, F. Azaiza, \& M. Wander-Schwartz (Eds.), Youth in Israel 2005. Tel-Aviv: Ramot Tel-Aviv University Publishers. (Hebrew)

Hertz-Lazarowitz, R., Farah, A., \& Zoabi, N. (2007). Identity maps of Arab and Jewish youth on Haifa University campus. Manual Development and Research Report, Haifa: The Faculty of Education and the Jewish Arab Center, Haifa University. (Hebrew)

Hertz-Lazarowitz, R., Yosef-Meitav, M., \& Zoabi, N. (2007). Identity maps of Arab and Jewish youth on Haifa University campus. Qualitative Research Report, Haifa: The Faculty of Education and the Je- 
wish Arab Center, Haifa University. (Hebrew)

Hertz-Lazarowitz, R., Yosef-Meitav, M., Farah, A., \& Zoabi, N. (2010). Draw your identity: Hyphenated Identity maps and interviews of Arabs and Jewish youth at Haifa University. Studies in Education, 3, -126 155. (Hebrew)

Hertz-Lazarowitz, R., Farah, A., \& Yosif-Meitav, M. (2012). Hyphenated identity development of Arab and Jewish teachers within conflict ridden multicultural settings. 10th Annual Conference of the Bulgarian Comparative Education Society (BCES) International Perspectives on Education, Kyustendil, 12-15 June 2012.

Hertz-Lazarowitz, R., Zelniker, T., \& Azaiza, F. (2010). Theoretical framework for cooperative participatory action research (CPAR) in a multicultural campus: The social drama model. Intercultural Education, 21, 269-279. doi:10.1080/14675981003760457

Hofman, J. E. (1988). To be Jews and Arabs in Israel. In J. E. Hofman (Ed.), Arab-Jewish relations in Israel: A quest of human understanding (pp. 154-175). Bristol, IA: Wyndham Hall Press.

Jarymowicz, M., \& Bar-Tal, D. (2006). The dominance of fear over hope in the life of individuals and collectives. European Journal of Social Psychology, 36, 367-392. doi:10.1002/ejsp.302

Katsiaficas, D., Hertz-Lazarowitz, R., Sirin, S., Fine, M., Yosef-Meitav, M., Farah, A., \& Zoabi, N. (2008). Mapping contested identities: Methodological implications for developing identity narratives. The 6th Annual Diversity Challenge, ISPRC, Boston College.
Leonard, H. S. (2003). Leadership development for the postindustrial, postmodern information age. Consulting Psychology Journal: Practice and Research, 55, 3-14. doi:10.1037/1061-4087.55.1.3

Maoz, I., Steinberg, S., Bar-On, D., \& Fakhereldeen, M. (2002). The dialogue between the "self" and the "other": A process analysis of Palestinian-Jewish encounters in Israel. Human Relations, 55, 931962. doi:10.1177/0018726702055008178

Rouhana, N. N. (2004) Group identity and power asymmetry in reconciliation processes: The Israeli-Palestinian case. Peace and Conflict: Journal of Peace Psychology, 10, 33-52.

doi:10.1207/s15327949pac10013 3

White-Stephan, C., Hertz-Lazarowitz, R., Zelniker, T., \& Stephan, W. G. (2004). Introduction to improving Arab-Jewish relationship in Israel: Theory and practice in coexistence education programs. Journal of Social Issues, 60, 237-252.

Yosef-Meitav, M. (2008). The construction of multiple identities in Haifa University: Do they create space for dialogue or conflict? MA Thesis, Haifa: University of Haifa.

Zelniker, T., Hertz-Lazarowitz, R., Peretz, H., Azaiza, F., \& Sharabany, R. (2009). Arab and Jewish students participatory action research at the University of Haifa: A model for peace education. In C. McGlynn, M. Zembylas, Z. Bekerman, \& T. Gallagher (Eds.), Peace education in conflict and post-conflict societies: Comparative perspectives (pp. 199-214). New York: Palgrave Macmillan. 